\title{
SITUACIÓN DE EDUARDO ANGUITA EN LA POESÍA CHILENA
}

\author{
POR \\ PEdRo Lastra \\ SUNY at Stony Brook
}

Aunque ésta no es la historia de mis emociones, como dice el narrador de "Tlön, Uqbar, Orbis Tertius", sino la de Eduardo Anguita como poeta chileno e hispanoamericano, debo empezar recordando una experiencia de lector, más entrañable que otras pues tuvo lugar horas después de escuchar la noticia de su muerte, ocurrida el 12 de agosto de 1992 en Santiago, y enterarme de las causas que la precipitaron: las quemaduras que había sufrido dos días antes al caer sobre una estufa encendida. Releí esa noche su Poesía entera -que apareció en 1971 en la colección "Letras de América", en la Editorial Universitaria de Chile - no sin detenerme de manera distinta en la breve nota que agregamos a continuación del Índice, resumiendo un apunte suyo:

La presente Anguitología (como la llama su autor) comprende obras en su mayoría inéditas y sólo algunas publicadas, aunque en escaso tiraje y ya agotadas. La Parte VII [titulada "Liturgia"] no ha sido concluida, de modo que nos limitamos a transcribir los fragmentos que Anguita nos proporcionó, ya que el total compone más de cien páginas a máquina y manuscritas, que, con mucha probabilidad, no serán jamás terminadas.

$\mathrm{El}$ autor ha querido agrupar sus poemas (que abarcan más de 25 años de poesía viva) según su naturaleza intrínseca, o formal a veces; y a fin que los que se interesen puedan pesquisar la evolución en el tiempo de una obra tan varia, hemos señalado en el Índice las fechas de cada composición.

La edición resultó muy desmedrada y sé que esto lo lastimó. Es posible que me haya atribuido algún descuido en ese aspecto del trabajo editorial - yo era el director de la colección mencionada- porque su laconismo se acentuó en casuales encuentros posteriores. Alguna vez traté de llevar el diálogo a ese difícil terreno pero me liberó gentilmente del esfuerzo: las erratas que había encontrado eran mínimas, y lo demás no tenía remedio.

Recordé esas circunstancias al releer Poesía entera, con la sensación de que ese lejano empeño había valido la pena. Reparé también en un detalle de esa nota, la mención a "una obra tan varia", porque ahora comenzaban a desplegarse en la lectura los múltiples poetas que parecían circular por el libro, como rostros, o más bien figuraciones y voces distintas del escritor que fue Eduardo Anguita. Al día siguiente escribí una página, de la que tomo algunos fragmentos para iniciar mi "situación" del personaje: 
La muerte lo sorprendió en el aislamiento en que había vivido — no acudo a la palabra soledad para mencionar esa condición distanciada y hasta hurafia de su existencia: para un creyente como él esa palabra tal vez no tendría el mismo sentido que para nosotrospero creo que no se sintió víctima de los demás. Al parecer, sus amigos fueron muy pocos, y su poesía suele registrar los nombres de esos pocos cuyo trato buscó: en primer lugar, Vicente Huidobro.

No figura, que yo sepa, en ninguna antología prestigiosa de poesía hispanoamericana del siglo $\mathrm{XX}$, ni aun en las que prodigan los nombres por las más diversas razones. Es seguro que Anguita desdeñaba toda causa de marginación que no fuera, para él, estrictamente literaria. Por eso, su ausencia de las listas consagratorias no logró distraerlo de sus preocupaciones mayores: La belleza de pensar, tituló el libro en el que reunió sus estimables ensayos y notas. ...

Al releer la obra poética de Anguita - uno de cuyos rasgos centrales es su dimensión metafisica - me ha impresionado profundamente la atracción multiplicada, constante, de una imagen que sólo ahora se me revela en su magnitud vaticinadora: la presencia del fuego, de lo ígneo, que lo esperaba al final de su vida. ${ }^{1}$

Durante muchos años, Eduardo Anguita fue considerado principalmente como un poeta del círculo de Vicente Huidobro, junto con otros pocos escritores de su tiempo, como los surrealistas del grupo "Mandrágora", cuya figura más notoria fue Braulio Arenas: una singular vinculación esta última, porque el creacionismo huidobriano establecía una distancia muy marcada con prácticas surrealistas como la escritura automática, punto nada insignificante - aunque por cierto tampoco el más esencial- de la propuesta bretoniana de 1924. Que alrededor de Vicente Huidobro se desarrolló una gran actividad literaria, para los jóvenes una veradera puesta al día en los experimentos de la vanguardia, es un hecho indiscutible. Eduardo Anguita lo señaló sin mezquindades en su prólogo a la primera antología dedicada a difundir la obra en prosa y verso de Huidobro, que él dispuso con apreciable rigor y buen sentido en 1943 y que la influyente Editorial Zig-Zag de Santiago publicó en 1945. En un pasaje testimonial de ese prólogo dice esto:

... nos dio a conocer lo que se realizaba en Francia y Europa, y que era para nosotros casi totalmente desconocido. Las tertulias y discusiones y lecturas de poemas hasta las 5 de la madrugada en casa del poeta durante cerca de seis años, quedarán en nuestra historia literaria como la última muestra de efervescencia y sensibilidad de este estremecido país (19).

En un párrafo anterior de la misma página había puntualizado:

... si en algo se probó la potencia de mi generación, fue que (cosa no fácil) pudo aprovechar todas las enseñanzas e influencias del maestro sin viciar en lo más mínimo sus sagradas individualidades y el tono personal de su obra: pues si hay una generación con más diversas personalidades, es la nuestra, siendo totalmente injusta la calificación de "huidobristas" con que se quiso adjetivar por igual a todas nuestras realizaciones estéticas.

\footnotetext{
'Inti, 36 (Providence, RI otoño 1992) 129. Entre las páginas 130-133 se incluyen nueve poemas de Anguita.
} 
Pero lo que nosotros le debemos a Huidobro no se podrá negar de ninguna manera. Él despertó una sensibilidad joven, que iba a responderle admirablemente, e instauró, por otra parte, una dignidad de "oficio" que, antes de él, no existía para los trabajos poéticos. A la, indisciplina —-desgraciadamente muy nuestra — opuso el rigor y la inteligencia, a que son tan afectos los artistas e intelectuales europeos.

Hasta aquí las tempranas observaciones de Anguita (a mi modo de ver muy certeras) con respecto a esas relaciones que iban a resultar enriquecedoras y productivas, sobre todo en su caso.

Porque reducirlo a él a una condición de epígono no sólo era injusto, como dice en ese prólogo, sino falso. Ahora, a tantos años del nacimiento y desarrollo de la aventura creacionista podemos ver que la poderosa y original personalidad de Anguita empezó a diferenciarse de Huidobro desde el primer momento, tanto en su práctica poética como en la reflexión sobre la teoría o doctrina que la sustentaba. Aunque simpatizara con la idea del "pequeño dios" o del "poeta mago" (y a menudo probó que sabía y podía jugar ese juego), su meta declarada fue llegar "a constituir la vida individual en una especie de liturgia, emanada directamente de la videncia (poesía escrita). El poeta no sólo vería de otro modo; sería de otro modo. De poeta habría pasado a sacerdote", según sus palabras. ${ }^{2}$

$\mathrm{Al}$ leer sus textos en 1986 con Enrique Lihn $^{3}$ advertimos que el sistema de preferencias elaborado por Anguita se contraponía al mismo tiempo al de Huidobro y al del surrealismo, pero con esta singularidad: que tal contraposición no lo llevó nunca a desatender las formas de producción verbal de esas instancias que lo prohijaron. Nuestra observación pudo resumirse así: "Ha creado la encrucijada en que se ha puesto, poniendo a prueba en ella su indudable capacidad de "imitación diferencial". Donde las vanguardias, y en particular Huidobro, postulan una competitividad con la máquina como ícono de lo moderno en la perspectiva de un "materialismo dialéctico" que se compadece con la imagen romántica del suplantador de Dios - capaz de crear en la poesía un mundo nuevo- Anguita se inclina desde una suerte de "religión del arte" a un arte religioso más y más ortodoxo". 4 Crear un mundo significaba entonces derivar de él una conducta, responder a la necesidad de una poesía práctica, abrir esa puerta "donde la poesía es capaz de dar un sentido al mundo y, con ello, un sentido a la existencia. Allí, Poesía y Religión se darán la mano", escribió en 1948. ${ }^{5}$

Voluntad diferenciadora: en años poco propicios a tales rigores no desdeñó la escritura de sonetos vanguardistas, por oposición al exclusivismo (y agreguemos, a los descuidos

\footnotetext{
${ }^{2}$ Eduardo Anguita, "El movimiento David", La belleza de pensar, 125 crónicas (Santiago de Chile: Editorial Universitaria, 1988) 131.

${ }^{3}$ Véase el dossier "Lectura de cierto poemas chilenos: Eduardo Anguita, Alberto Rubio, Óscar Hahn, Manuel Silva Acevedo, Diego Maquieira. Selección y notas de Enrique Lihn y Pedro Lastra. Hora de Poesía, 51-52 (Barcelona: Lentini Editor, mayo-agosto 1987). Sobre Anguita, páginas 811. Estas páginas fueron reproducidas en el suplemento "Literatura y Libros" del diario La Época, 18 (Santiago, 14 agosto 1988) 4-5, con motivo del Premio Nacional de Literatura que le había sido otorgado recientemente.

${ }^{4}$ Dossier 9.

${ }^{5}$ Hugo Zambelli editor, "La poesía", 13 poetas chilenos (1938-1948) (Valparaíso: Imprenta Roma, 1948) 11-12.
} 
culpables) del verso libre. El rasgo vanguardista era tenue, y tanto, que se manifestaba como acotación parentética situada al margen, como subtítulo lateral: los que integraban la serie "Sonata marina", por ejemplo, traían estas anotaciones: "(Posición de combate del viajero)", "(Litoral de la sirena)", "(Labrador de mar)", etc. No todos son memorables, desde luego, pero siempre revelan una artesanía exigente, como los titulados "Soneto 1942" y "Pintura de Luis Herrera Guevara".

Otra resistencia significativa pudo verse en 1948, cuando escribió su poema elegíaco como "Mester de Clerecía en memoria de Vicente Huidobro".

La situación que originaba ese poema y su fe religiosa explican la opción por la rigurosa forma del "mester de clerecía" en este homenaje, pero acaso inconscientemente Anguita tenía en cuenta que el maestro se había inclinado por la actitud del juglar en su novela Mio Cid Campeador (Hazaña), publicada en 1929. La nota que sigue al título de la elegía - "(Por encargo de Gonzalo de Berceo)"- atrae algún eco de la alacridad huidobriana, pero luego contrasta con ella la gravedad intensa y desolada del texto, desde la primera cuaderna vía:

A muerto de los aires un fino emperador.

Escuridad est tanta que non a alrededor.

Los sones han callado ca murió el roseñor

Que era entre todas aves el pájaro meior.

Y esto, sin necesidad de insistir en que el final del "Mester ..." dice algo más a sus lectores de hoy: no sólo el lamento sino también el presagio:

Mi Señor Jesuchristo, mi Padre e Redemptor,

Io ruego que me invites al concierto maior,

Fagas en la mi carne plagas de grant dolor

Ca non est instrument sin roturas de amor.

Las muestras de la dialéctica de cercanía y resistencia a la poética creacionista pueden multiplicarse, rastreando una actitud u otra incluso en manifestaciones aisladas de destrezas ejercitadas, sin duda, en el contacto cotidiano con Huidobro. En el fragmento terminal de "Naturaleza del amor", por ejemplo, se dibuja la imagen de un hablante que no sólo se mira escribir y reflexiona al pasar sobre una determinada palabra, sino que levanta de pronto la vista de la página, por así decirlo, para enfrentar y contradecir al lector convertido súbitamente en un interlocutor directo:

lo invisible es lo mejor a pesar que no aparentas

creerlo

en el amor hay una vena

que juega un papel extraño

un papel extraño como un ángel

aportando sacos de invisibilidad

qué palabra tan dificil 


\author{
a las manos que buscan lo duro \\ lo susceptible de llegar hasta la evidencia \\ hasta el cuerpo propio hasta la corteza interna \\ hasta la consumación de uno en uno hasta la confusión \\ de los dos lados en un solo lado \\ eso no es amor señor usted está confundiendo \\ eso no es amor es hueso obstinado.
}

Éste es un poema de 1935, la misma fecha del relato Un año de Juan Emar, donde el personaje narrador del episodio correspondiente al mes de enero decide subir a una torre para contemplar la ciudad desde lo alto, y describe el comienzo de su empresa de esta manera: "Empecé a trepar. Pero a la altura del vigésimonono peldaño di un trastabillón (¡qué linda palabra!) y La Divina Comedia se me soltó de bajo el brazo y rodó”. 6

"... qué palabra tan difícil"; "(iqué linda palabra!)": el gesto de quien habla en los textos es el mismo, pero más allá de la comprobación de una semejanza expresiva lo que interesa es indagar qué sentido, o sentidos, tiene ese gesto. Uno de ellos podría ser éste: conciencia del artificio literario y, parejamente, conciencia de la suprema libertad de ese artificio. También, rupturas del sistema, de tempranero carácter antipoético.

Otra verdad a medias en la escasa crítica sobre Anguita ha sido su adscripción al surrealismo. También en este caso hay buenas razones para hablar de cercanías y resistencias. Ya se sabe que el surrealismo dejó una huella significativa en Chile, y hasta cierto Huidobro - el de Temblor de cielo- podría ser releído desde ese mirador (aunque sin olvidar los versos famosos: "el vigor verdadero / reside en la cabeza"); conviene sin embargo señalar los límites de tales relaciones.

Anguita fue parco para referirse a ellas. En sus diálogos con Juan Andrés Piña, al hablar de los surrealistas de "Mandrágora" apunta con brevedad: “... yo pensaba distinto que los surrealistas e incluso era contrario a varios de sus postulados".7 Más reveladora es su respuesta a Piña sobre el papel que juega el inconsciente en el proceso creativo: "Tiene una función primordial - dice Anguita- sobre todo en los poetas de vanguardia, sean o no surrealistas. En mi caso particular, he sostenido que mi Inconsciente es muy rico y mi Conciencia es muy hábil, porque exige explicaciones". ${ }^{8}$

Como expresión de autoconocimiento estas líneas son, más que suficientes, muy notables, y creo que su escritura poética lo corrobora casi siempre. No así sus cuentos de Inseguridad del hombre (1949), relatos oníricos en los cuales prescindió del papel ordenador de la conciencia y se negó a darle explicaciones, con resultados que a mí me parecen muy precarios. ${ }^{9}$ Pero en sus poemas no ocurre lo mismo, porque en ellos la conciencia cumple,

\footnotetext{
${ }^{6}$ Juan Emar, Un año (Santiago de Chile: Editorial Zig-Zag, 1935) 7.

${ }^{7}$ Juan Andrés Piña, "Eduardo Anguita, poesía y hechicería", Conversaciones con la poesía chilena. Nicanor Parra, Eduardo Anguita, Gonzalo Rojas, Enrique Lihn, Óscar Hahn, Raúl Zurita (Santiago: Pehuén, 1990) 67.

${ }^{8}$ Juan Andrés Piña, Conversaciones ... 78.

${ }^{9}$ Lo que puede rescatarse de esos textos son notas flotantes, aquí y allá, válidas como imágenes o fugaces lugares poéticos: "... la vida es la vida y el viento la gasta", o "Era un día con todos los caracteres de la noche", se lee en el desmadejado relato "Animal en angustia". Y en "La muerte
} 
como se espera, el rol constructivo que le asigna Anguita y que con otras palabras definió -también memorablemente-Dylan Thomas al razonar su "profundo desacuerdo" con las pretensiones surrealistas:

A mí no me importa de dónde salen las imágenes de mis poemas; que salgan, si usted quiere, del mar más hondo del escondido yo; pero antes de que lleguen al papel deberán atravesar todos los procesos racionales del intelecto. Los surrealistas, por otra parte, acomodan sus palabras sobre el papel, exactamente como emergen del caos; no trabajan esas palabras ni las ordenan; para ellos el caos es la forma y el orden. A mí, esto me parece excesivamente presuntuoso; los surrealistas imaginan que cualquier cosa que draguen de sus yo subconscientes y la plasmen en pintura o en palabras debe esencialmente ser de algún interés o valor. Yo niego eso. Una de las artes del poeta es hacer comprensible y articular lo que pueda emerger de las fuentes subconscientes; uno de los usos más importantes del intelecto es seleccionar, de la masa amorfa de las imágenes subconscientes, aquellas que mejor logren su propósito imaginativo, que es escribir el mejor poema que se pueda. ${ }^{10}$

Es posible, igualmente, estar en desacuerdo total o parcial con tales afirmaciones, pero a condición de reconocerles la oportunidad de un llamado al orden contra los absolutismos de escuelas o tendencias: un mérito que debe concederse desde luego a la conducta poética de Eduardo Anguita.

Uno de sus poemas mayores, titulado "Definición y pérdida de la persona" (escrito en 1940 y publicado en 1948 en la antología de Hugo Zambelli) ilustra muy bien esa conducta.

Precedido por un sugestivo epígrafe de Hölderlin, el extenso poema despliega la vivencia de un éxtasis, descrito por el poeta en el "Prefacio" como "el gozo [que experimenta el ser] al vivir por fin la realidad, después de haber morado en el vacío. Al final -agrega Anguita - el poema se plantea como pérdida". Y la reflexión conclusiva del prefacio es ésta "Eternidad, tiempo, eternidad, tiempo. Rayado por estos dos túneles alternos, una hermosa zebra es el hombre".

La última imagen es una ocurrencia feliz, que funde con eficacia consumada el humor y la gravedad, y cuya génesis es muy clara en el orden de las asociaciones. Pero a mí me parece también una lección de rigor y del control verbal de la conciencia hábil y exigente de Anguita, porque allí donde un poeta menos cuidadoso hubiera prodigado literalmente una selva a partir de un hallazgo tan provocativo, el texto se detiene en esa formulación lapidaria.

"Definición y pérdida de la persona" es uno de los textos más complejos de Anguita, pues intentó en él un "difícil trabajo" - así lo califica él mismo- como fue el tender poéticamente un puente entre lo que podía intuirse como "el reconocimiento que un Dios

nocturna": "La cortina se mueve, sin aire que la impulse. Es una mano de aire; detrás viene el cuerpo del desconocido que trajina los sueños".

${ }^{10}$ De las respuestas de Dylan Thomas a un cuestionario que le fue presentado por un estudiante en 1951, y publicado posteriormente en Texas Quarterly, Winter 1961, con el título "Dylan Thomas's Poetic Manifesto". Véase Constantine FitzGibbon, The Life of Dylan Thomas (Boston: Little Brown and Company, 1965) 327-328. Cito la traducción de Gabriel Rodríguez, revista Oráculo, 2 (Lima, 1979) 71. 
hace del mundo que ha creado o que podría haber creado hace mucho tiempo" y las formas que se manifiestan, por lo menos en el plano de la temporalidad, como lo real, y en esas formas, el hombre mismo en primer lugar. Tan ambicioso e intenso proyecto poético no es fácil de analizar, y es probable que los juicios que suscite surjan siempre de valoraciones parciales. Las mías atienden a momentos de alta tensión expresiva, que llegan al lector como ondas fluctuantes entre la liturgia y el vaticinio. Citaré como ejemplo sólo el final del largo poema, cuya acotación lateral (¿un eco de las prácticas escriturales de algunos poetas metafísicos ingleses?) dice:

El poeta se pone de pie y reza:

Y luego estos versos, que residen ya en la memoria de varios de sus lectores:

"Dios mío, ¿dónde es el dónde? ¿Qué pregunta soy?"

Con tranquilidad, con tranquilidad; con furia y tranquilidad.

"Habíamos permanecido demasiado tiempo en la vida y creímos que eso era natural".

Ahora va a ser tarde: es tarde, brumas mías.

Con la palabra "Liturgia" Anguita tituló la sección que contenía sus últimos textos. Los diversos caminos que recorrió como si él fuera al mismo tiempo diversos poetas, confluyeron allí en un tipo de poemas que él definió como "católicos en su sentimiento primordial": Será necesario retener esta idea para entender cabalmente su empeño.

En efecto, la dirección final de su escritura, así enunciada, parecería invocar la mayor gravedad, distanciada de las audacias e irreverencias que caracterizaron a la vanguardia literaria, de la cual se sintió siempre parte. Pero hay que agregar que en Anguita esas actitudes no fueron un gesto, sino una manera realmente asumida de vivir y de escribir. Por eso es que algunos poemas de "Liturgia" plasman contenidos religiosos muy trascendentes acudiendo a una alianza entre ortodoxia católica y la heterodoxia vanguardista. El resultado fue, una vez más, poéticamente feliz en la producción de un escritor que no se dejó tentar por la pura exterioridad de lo que Borges llamaba "novedades ruidosas"; en otras palabras: allí donde el vanguardismo exigía un vino nuevo en odres nuevos, Anguita reclamó para su uso el vino viejo en odres nuevos.

El poema dramático "Única razón de la pasión de N.S.J.C." ilustra esta alianza con brillantez, ingenio e intensidad infrecuente en nuestra poesía.

La voz central en esta pieza es la de Arlequín, figura transhistórica de la Comedia del Arte, como se sabe, pero que le procuró a Anguita el margen de libertad heterodoxa que podía permitirse en sus poemas litúrgicos. El discurso dislocado de esa figura empieza por diferenciar caóticamente a los beneficiarios del sacrificio divino, distribuyéndolos entre nombres propios de personas reales de la vida chilena (algunos, amigos cercanos de Anguita como Jenaro Medina, el Chico Molina, etc.) y otros en cuya enumeración se confunden los gentilicios con la mención de grupos heterogéneos (ciegos, gordos, sabios, egipcios atletas, liberales, utopistas, explotados ...). En el diálogo con el coro, que repite la enumeración totalizadora de Arlequín, éste centraliza la razón disputada entre lo colectivo y lo personal, 
zanjándola en beneficio del yo, con lo que en otra publicación que Anguita aprobó ${ }^{11}$ llamamos "un gesto de rapacidad anticristiana". El coro de hombres primero y luego el coro de mujeres abren el pronombre a la propiedad común, colectivizando y restableciendo paradójicamente la comunidad de ese misterio.

Con este poema Anguita demostró que podía ser también un humorista consumado si se lo proponía; pero sin duda contaba con que se entendería la seriedad profunda que subyacía a ese humor.

Hay otro registro en los poemas de "Liturgia", que se lee ahora en la dimensión del vaticinio o de las anticipaciones: es el que atrae las imágenes del fuego, de la llama, del incendio y la ceniza. Parecía natural que en estos poemas finales, y aun en los anteriores, esas imágenes propias del campo semántico de lo ígneo - y cuya vieja simbología religiosa es múltiple y rica- recurrieran hasta el punto de sobresalir en la escritura de Anguita con el carácter de signo valorizado, en el sentido que Pierre Guiraud le da a esa noción en su análisis de textos poéticos de Baudelaire. En Poesía entera se pueden señalar más de cincuenta menciones de tales imágenes, y a menudo en lugares muy centrales, estratégicos, del poema. Por su situación y su frecuencia resultan inquietantes para el relector de Anguita; pero tal vez ninguna lo sea más que éstas, en la cual otro y el mismo Arlequín de "Única razón de la pasión ..." teje sus obsesiones al comienzo de "Misa breve":

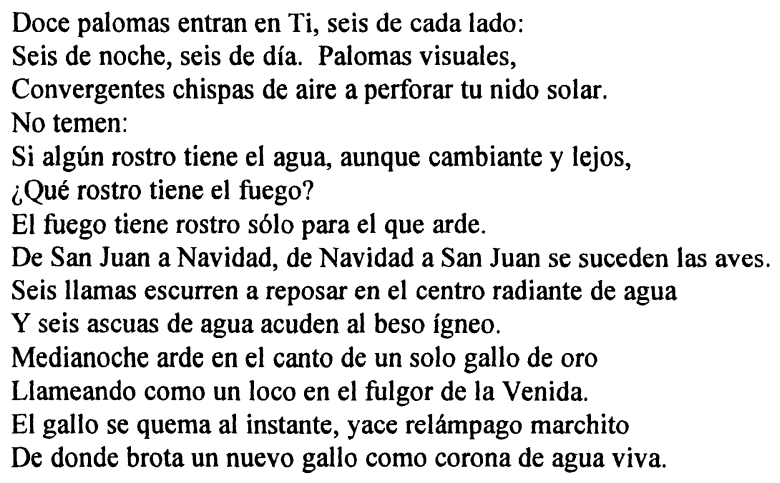

De donde brota un nuevo gallo como corona de agua viva.

Después de un recorrido - aun fragmentario y parcial - por la poesía de Anguita, sorprende que una personalidad literaria tan rica, variada y compleja haya sido casi ignorada en el espacio crítico de su país, y del todo fuera de él: es cierto que los artículos apreciativos de José Miguel Ibáñez ${ }^{12}$ y el díalogo con Juan Andrés Piña son excepciones valiosas que

\footnotetext{
${ }^{11}$ Me refiero a la lectura mencionada en la nota 3, que aquí sigo, y que Anguita consideró "justa y justiciera", según me dijo en nuestro último encuentro, en Santiago, el 10 de julio de 1988 ("Algo, que ciertamente no se nombra / con la palabra azar, rige estas cosas").

12 "Poesía entera de Eduardo Anguita" y "Anguita: Venus en el pudridero" en su Poesía chilena e hispanoamericana actual (Santiago de Chile: Editorial Nascimento, 1975) 234-238 y 239-244. Su
} 
ponen a prueba una regla sombría del ocultamiento y la pereza; pero es muy poco lo que puede agregarse a ellas, a pesar del Premio Nacional de Literatura que le fue concedido en 1983.

Con los escritores no le ocurrió lo mismo. Anguita fue leído y respetado por ellos, y yo creo que eso le bastaba; como buen lector de Conrad recordaría más de una vez este párrafo sobre la disciplina del escritor, y se reconocería en él: "Debe hacer su trabajo lo mejor posible, ser exacto y cuidar sus frases como una tripulación lava su puente; no debe aguardar otra recompensa que el silencioso respeto de sus iguales; tal es su honra".

De mi generación sé decir que fue parte de su pequeño público. Su ahora buscada Antologia de poesía chilena nueva, publicada en 1935 en coautoría con Volodia Teitelboim, fue un breviario de sugestivas novedades, y no sólo en esos años. Yo, que la leí en provincia en una época de lentas comunicaciones, puedo testimoniarlo. ${ }^{13}$

Algunos de nosotros hemos tenido también una especie de Anguitología para uso personal, constituida por versos o fragmentos felices e incisivos, con frecuencia de estirpe creacionista pero nunca sin un fulgor de intensidad metafísica, como el que cité al referirme a "Definición y pérdida de la persona". Muchos de ellos proceden de sus poemas tempranos, como "Animales e inscripciones", que dedicó a Rosamel del Valle ("Vienes y ves a los amigos del tiempo / A los que hacen del tiempo su muerto preferido") o de "Mi muchacha se va a casar", donde el carácter inesperado y oblicuo de las alianzas genera la vacilación de las certidumbres del lector ("Deseo estar contigo para dudar de mí / Porque el amor es una irrealidad / Apta para comprobarnos"); o de un notable poema posterior - "El verdadero momento"- que yo leo como una puesta en escena de las trampas de la memoria, esa arena movediza que el diccionario define como "la facultad de conservar las ideas y las imágenes" y que el hablante de Anguita vuelve a contradecir, dibujándola como lo que es para el sujeto que recuerda: un puro espacio ilusorio, donde nunca se coincide con "el verdadero momento"; el lugar, dice, en el cual estamos "condenados a fantasear / como los concéntricos círculos de un estanque en que un torpe / arroja piedras interminablemente".

Estas breves muestras de una escritura al mismo tiempo aspasionada y lúcida permiten señalarla con palabras de Fernando Pessoa - un autor tan desplegado que Anguita debió

último artículo, "La poesía de Anguita: una perspectiva", "Revista de Libros" de El Mercurio, 172 (Santiago, 16 agosto 1992) 5.

${ }^{13}$ Comentamos brevemente ese libro al iniciar nuestra lectura de 1986 (véase nota 3). La agitada polémica que generó la publicación de la antología está muy bien documentada en el libro de Faride Zeran, La guerrilla literaria. Huidobro, de Rokha, Neruda. (Santiago de Chile: Ediciones BAT, 1992).

Habrá que volver más de una vez a la propuesta que Eduardo Anguita y Volodia Teitelboim se atrevieron a hacer en 1935, reduciendo la "selva lírica" —éste fue el título de un libro singular, publicado en 1917 por Julio Molina Núñez y Juan Agustín Araya - a los nombres de Vicente Huidobro, Ángel Cruchaga Santa María, Pablo de Rokha, Rosamel del Valle, Pablo Neruda, Juvencio Valle, Humberto Díaz Casanueva, Omar Cáceres, Eduardo Anguita y Volodia Teitelboim. "El tiempo, como Huidobro en su momento, le ha dado su aprobación relativa. De los diez poetas antologados puede decirse que están, salvo error u omisión, en la historia de la poesía chilena" (Dossier 8). 
haberlo visto como una figura ejemplar - y que se encuentran en una carta dirigida en enero de 1915 a uno de sus compañeros de la revista Orpheu:

Llamo insinceras a las cosas hechas para asombrar, y a las cosas, también -fijese en esto, que es importante - que no contienen una fundamental idea metafisica; esto es, por donde no pasa, aunque sea como un viento, una noción de la gravedad y del misterio de la vida.

Las mejores páginas poéticas de Eduardo Anguita siguen siendo agitadas por ese aire de gravedad y de misterio. 